\title{
¿LA SOLUCIÓN FINAL A LA «CUESTIÓN FEMENINA»? *
}

\author{
Hilda Lass
}

Marx y Engels habían sostenido que la situación de inferioridad de las mujeres era producto de la aparición de la propiedad privada. Una vez suprimida ésta, tendría lugar la rehabilitación de la mujer. Sin embargo, esto no parece haber sucedido en los países de Europa del Este luego de sesenta años de revolución. Si bien la mujer se ha integrado en grandes proporciones a la fuerza de trabajo, lo hace en las profesiones marginales y peor pagadas. Tampoco ha habido ninguna modificación sustancial en el rol doméstico de la mujer en el hogar. Más aún, cuando los intereses demográficos lo exigen, los estados socialistas han vuelto atrás en su política de divorcio, aborto, anticonceptivos y derechos de la mujer.

Esta situación contrasta con la sueca. Si bien el caso sueco aparece como muy poco seductor tanto para la vieja izquierda como para la nueva, Suecia es el país que ha llevado más lejos su legislación sobre la igualdad entre hombre y mujer tanto de derechos como de deberes.

* Reproducido de Les Temps Modernes, vol. 363 (octubre 1976). 
En Occidente, en el curso de estos últimos años, la aparición de la doctrina marxista, aliada al nacimiento del movimiento de las mujeres, es un factor importante de optimismo en lo que se refiere al poder del socialismo contra las injusticias a las cuales las mujeres han estado sometidas durante siglos. No hay más que considerar la agudeza con que Marx y Engels preveyeron, en una especie de sorprendente premonición, los efectos de la industrialización sobre las mujeres y sobre la familia.

Presintieron que detrás de la aparente nocividad de la revolución industrial del siglo xIx hacia la nueva clase obrera, y particularmente hacia las mujeres y los niños, se perfilaba para las mujeres la esperanza de una posible liberación decisiva. También comprendieron que, contrariamente a lo que se creía, la familia no era una institución inmutable, y que la familia patriarcal del siglo xIx, cuya función era la de consolidar la propiedad, podía ser reemplazada por una familia donde las mujeres fueran económicamente y socialmente libres.

Consideraban que el trabajo fuera del hogar era la condición primera para la independencia de las mujeres, y predijeron que esto no sólo necesitaría la implantación de garantías legales para las mujeres, sino que también obligaría a la sociedad entera a responsabilizarse sobre el cuidado de los niños y de los hogares haciendo de todo ello unas «industrias públicas».

En los países de la Europa del Este, la prueba ha sido hecha recientemente en el sentido que el movimiento socialista y radical de las mujeres, que se había apoyado sobre estos principios revolucionarios y desde el principio se había desembarazado de una buena parte del misticismo sentimental ligado al rol sagrado de esposa y de madre de la mujer, pueda servir de instrumento para justificar las ilegalidades, y constatar que, en los países socialistas de la Europa del Este, las viejas ideas estereotipadas están todavía allí bajo la nueva organización.

Las mujeres occidentales que visitaron los países socialistas en el curso del Año Internacional de la Mujer, se dieron cuenta de que, a pesar de 
que las mujeres socialistas habían dejado de estar confinadas en sus hogares, a pesar de que habían dado pruebas de sus capacidades en todas las profesiones, estaban manifiestamente ausentes de los lugares de poder real. En los países donde sólo efectúan la mitad, o casi la mitad, de los trabajos de fuerza, las mujeres hacen, en su mayoría, como en todas partes, los trabajos de rutina mal pagados. Sólo tienen, como en cualquier parte, un rol de representación en los cuerpos constituidos donde se toman las verdaderas decisiones. Al mismo tiempo, como en cualquier parte, sólo pueden esperar de sus maridos o del Estado una ayuda mínima en su lucha contra las formas arcaicas del trabajo doméstico.

A alguien que, como yo, ha visto desarrollarse esta paradoja en un país del bloque del Este, Checoslovaquia, es evidente que uno de los factores importantes de este Estado de hecho es la firme negativa de los partidos comunistas de la Europa del Este de intentar barrar el paso teóricamente de manera creativa al análisis original de Marx y Engels sobre la posición de las mujeres, análisis que sólo era secundario en lo esencial de su trabajo, y que se basaba sobre una reconstrucción evolutiva de la sociedad prehistórica que las profundas investigaciones de la antropología social moderna no han confirmado.

Pero hay otro aspecto de este panorama. Aunque los autores de las numerosas leyes y medidas sociales o de educación que han concedido a las mujeres de los países socialistas la mayor parte de las condiciones favorables a la igualdad con los hombres, eran socialistas idealistas, la aplicación actual de estas leyes y de estas medidas ha sido subordinada por los dirigentes economistas y políticos a unos «proyectos de más alto interés nacional». Estos dirigentes consideraron ante todo a las mujeres como una fuerza de trabajo, lo que les ha conducido a invertir los objetivos liberadores de esta política.

Cuando, después de la Segunda Guerra Mundial, los gobiernos comunistas llegaron al poder en la Europa del Este, heredaron de la Unión Soviética una fórmula ya preparada para conseguir la solución final a la cuestión de la mujer. Friedrich Engels, en su Origen de la familia, de la propiedad privada y del Estado, había estudiado (siguiendo las notas detalladas de Marx) la historia de la opresión de las mujeres hasta sus orígenes, que eran según él los orígenes de la propiedad privada, allá por la prehistoria. La derrota de las mujeres había tenido lugar, escribía, cuando el patriarcado había derribado al matriarcado igualitario, cosa que había sido necesaria para conservar la propiedad en la estirpe masculina. La mujer sería rehabilitada al lugar que le correspondía de derecho cuando las relaciones entre la propiedad privada y el patriarcado fuesen derribadas por el socialismo. 
A pesar de que muchos acontecimientos tuvieron lugar en las ciencias sociales y en las ciencias naturales desde que Marx y Engels avanzaron esta hipótesis, la emancipación socialista de la mujer sólo ha evolucionado en una parte del mundo donde la investigación científica no puede avanzar si no es en la medida que pueda confirmar las palabras de los «fundadores de la ciencia marxista». El hecho de insistir sobre una simple relación de causa a efecto entre el sistema del provecho y la opresión de las mujeres, permite evitar (y nos impide siempre) la exploración, o incluso el reconocer otros obstáculos económicos en la igualdad.

Si examinamos la interpretación marxista de los años 50 , la igualdad estaba ya conseguida. Se habían socializado los medios de producción; se había implantado la igualdad jurídica y los programas sociales y sanitarios totales. La mujer estaba, pues, preparada para tener su puesto al lado del hombre en cualquier ocasión. Un número creciente de guarderías y parvularios se ocuparía de los niños pequeños. Los restaurantes públicos, los servicios de limpieza, las lavanderías que por el momento eran casi inexistentes pero que aumentarían en los futuros planes quinquenales, se encargarían paulatinamente de hacer los trabajos domésticos.

Todo ello se situaba en el espíritu inicial del determinismo económico, sin que fuera discutido lo que significaba realmente la igualdad. Los hombres, las mujeres y los niños sólo tenían que transformar los roles y las imágenes que de sí mismos habían adquirido a lo largo de los siglos, en función de la interacción compleja de las realidades biológicas, psicológicas, sociales y económicas. Y esto tenía que ocurrir no a consecuencia de unas discusiones, de un trabajo teórico creativo, de la educación, de ensayos y de errores, sino simplemente porque los bancos y las fábricas habían pasado de una mano a otra. La conciencia socialista debería alcanzarse ante todo por la integración de los hombres y de las mujeres a las relaciones de producción socialistas. Las organizaciones nacionales de mujeres fueron disueltas puesto que ya no eran necesarias.

En Checoslovaquia, como en todos los países socialistas, la concretización del derecho de las mujeres a trabajar en igualdad con los hombres coincidió con la necesidad de mano de obra en un momento en que unos planes de expansión industrial ambiciosos llegaban hasta unas regiones donde la mayor parte de la población se dedicaba aún a la agricultura, donde la productividad era débil, y donde la fuerza de trabajo de los hombres había sido diezmada.

La situación no era tan crítica como la de la Unión Soviética, donde en 1949 las mujeres representaban el $60 \%$ de la población activa. En la mayoría de los países de la Europa del Este, la mano de obra había sido diezmada por las pérdidas alcanzadas en tiempos de guerra y la 
deportación de las poblaciones, lo que no impidió que Checoslovaquia, por ejemplo, expulsara a dos millones y medio de sujetos de raza germánica después de la guerra, en el momento de los Acuerdos de Potsdam.

Entre 1948 y 1965, el empleo de las mujeres en Checoslovaquia aumentó en un $40 \%$, y durante este último año, las mujeres representaban ya el $45 \%$ de la fuerza de trabajo. A todo esto se añade el hecho de que en el mismo período, más de medio millón de mujeres dejaron su granja por trabajos que no eran agrícolas, creando así un problema específico en el trasplante de costumbres rurales a las ciudades.

En lo que concierne al trabajo, las mujeres solteras fueron sometidas a los mismos requisitos legales que los hombres. Las mujeres casadas iban al trabajo como signo de emancipación, por deber patriótico, o simplemente porque tenían necesidad de dinero. La presión que tuvieron para que ejercieran un oficio fue implacable, y como la industria pesada en pleno desarrollo ocupaba a todos los hombres disponibles, es por pura matemática que muchas se encontraton en sectores de trabajo poco habituales.

Los planes económicos elaborados en el curso de este período prometieron que los servicios de ayuda pública serían acrecentados en proporción al crecimiento del número de empleos femeninos, pero esto no ocurrió así. Asimismo, después del XX Congreso del Partido Comunista de la Unión Soviética en 1956, y de sus revelaciones sobre los errores stalinistas, fue necesario esperar mucho tiempo para que emergiera una imagen relativamente objetiva de la verdadera situación de las mujeres en lugar de las fotografías de jóvenes obreras trabajando en un torno y de los pósters donde hermosas granjeras llevaban en un brazo a su hijo $y$ en el otro un haz de espigas de trigo.

No es hasta principios de los años 60 con la primera y tímida rehabilitación de la demografía, de la sociología y de la psicología, cuando los «problemas de las mujeres» llegaron a ser objeto de debates en los mass media de los países socialistas, e invadieron las reuniones de las cámaras de comercio, de las instancias educativas y científicas, y después alcanzaron las altas esferas del Partido y del gobierno de estos países.

Una vez levantada la tapa de la caja de Pandora, las quejas que se vertían de ella parecían inagotables. Todos aquellos años durante los cuales la industria pesada se había comido la parte del león en los recursos a expensas de los bienes de consumo y de los servicios, habían transformado la más simple tarea del hogar en un ejercicio de logística.

El diagnóstico de los médicos revelaba a mujeres con surmenage, más propensas a las enfermedades nerviosas que los hombres, a niños cansados por unos horarios de guarderías demasiado pesados y porque 
se les enviaba a la escuela demasiado pronto cuando aparecían síntomas de enfermedades. Los empresarios dieron la culpa a sus empleadas «con las cuales no se podía contar». Cuando su ausencia no era debida a un período de maternidad, se pasaban el tiempo cuidando a su hijo enfermo - prolongaban la pausa de la comida para ir a comprar ropa, naranjas o calcetines de lana.

Yo me acuerdo de haber oído, en una conferencia de prensa para el restablecimiento del sindicato de mujeres en 1967, a la presidente del Comité de mujeres de Checoslovaquia decir, haciendo alusión al trabajo que había sido hecho para el reclutamiento de mujeres en la industria y en la agricultura: «Hemos hecho nuestro trabajo. Los problemas se han acumulado por encima de nuestras posibilidades.»

Al examinarlo de cerca, ell rol de las mujeres en la industria no se parecía en nada a la imagen que se hacía de él el movimiento revolucionario de mujeres, y no tenía nada que ver tampoco con aquellas historias de interés de la humanidad que habían aparecido durante muchos años en la prensa de la Unión Soviética, y en el curso de estos últimos quince años en los media de los otros países socialistas. La igualdad de posibilidades concedida a personas que no partían de las mismas premisas, no produjo la igualdad, y no se encontraron más mujeres para trabajar al lado de los hombres en un mismo empleo.

En algunos sectores no tradicionales, como por ejemplo la siderurgia y los servicios civiles estatales, las mujeres de más edad fueron empleadas como trabajadoras no cualificadas y no encontraron mucho tiempo para cualificarse y obtener mejores puestos de trabajo. Las mujeres jóvenes que entraron en estas industrias como aprendizas no terminaban normalmente su formación, y si lo hacían, no resistían mucho tiempo en el sector.

La atmósfera hostil de una fábrica diseñada por hombres, y destinada a los hombres, un proceso de producción que no dependía de nada relacionado con su pasado, y una extensa gama de actitudes sexistas que se encontraban en sus compañeros trabajadores, en los encargados, en los directores, era más de lo que podían soportar las adolescentes. Lo que ellas deseaban ante todo era lo que sus padres esperaban de ellas: aprender peluquería, a coser, decoración, la fabricación de joyas o la decoración de escaparates.

Como puede comprenderse, las industrias «no tradicionales» empezaron a rechazar a las jóvenes.

Es verdad que el número de mujeres que terminaban sus estudios secundarios, que iban a la universidad, que trabajaban en la industria -la mayoría en puestos que antes ocupaban los hombres- había au- 
mentado. Sin embargo, cuando los economistas y los sociólogos examinaron el problema más de cerca, descubrieron que las mujeres estaban concentradas de forma aplastante, en un número restringido de sectores mal pagados. Las mujeres representaban a la mayoría de los trabajadores de la sanidad y de la ayuda social, de la administración, del comercio al detalle, de los abastecimientos, de la industria textil, del calzado y de la piel, del vestido y de la alimentación. $E$ incluso en estos sectores, tenían los puestos peor pagados con el mínimo de responsabilidades; los puestos de responsabilidad o los puestos mejor pagados iban a parar a los hombres, incluso cuando las mujeres mejor cualificadas que ellos los solicitaban.

El coup de grâce a la idea de que las mujeres no iban a tardar mucho en alcanzar su sitio al lado de los hombres en todas las profesiones, fue dado cuando se descubrió que las leyes liberales de los países socialistas sobre el aborto, adoptadas entre 1.955 y 1957 para eliminar el aborto ilegal, habían hecho del aborto un método privilegiado de regulación de nacimientos. En 1966, Checoslovaquia registraba 2 abortos por cada 5 nacimientos, Hungría 4 por cada 3, mientras que un estudio sobre las tasas de aborto de Leningrado demostraba que esta ciudad, sobre $5 \mathrm{em}$ barazos, 4 terminaban en aborto. La tasa de natalidad de los países de la Europa del Este había descendido del $25 \%$ (en Bulgaria) hasta el $45 \%$ (en Polonia y en Rumanía) en diez años.

Las estadísticas indican ahora que las mujeres que trabajaban tenían menos niños, y que las mujeres estaban obligadas a trabajar para poderse permitir el tener niños, lo que estaba en conflicto con la ideología stalinista según la cual una ley de crecimiento de la población adaptada al socialismo debería necesariamente conllevar familias más numerosas. Algunos países cuyas necesidades de mano de obra indígena no mostraban ningún signo de debilidad, tuvieron que afrontar una disminución del crecimiento de la población cuando las niñas nacidas después de la ley sobre el aborto tuvieran edad de tener niños. Contrariamente a los países capitalistas occidentales, donde una tasa de natalidad bastante baja se había estabilizado desde hacía algunos años, los países de la Europa del Este no estaban preparados para resolver el problema a través de la inmigración.

Mientras que todo el mundo miraba desde el otro lado, el rol indispensable de la mujer en la producción se había desbaratado contra su rol indispensable en la reproducción. Quedaba claro que el exceso de simplificación en los años 50 había resultado ineficaz. Las nuevas relaciones de producción no habían originado nuevas relaciones entre los hombres y las mujeres. Las mujeres no tomaban gusto a la tecnología 
como los patos al agua, por simple contacto con ella. Los niños no prosperaban automáticamente en cualquier colectivo. Las industrias de ser. vicio no conseguían cumplir sus promesas.

Después de algunos decenios de esterilidad teórica, las tentativas que se hicieron para definir un «estilo de vida socialista» y el rol de la mujer en este estilo de vida, no tuvieron ningún efecto de cara a la solución de esta situación de crisis. Al contrario, la investigación médica y social sostenía habitualmente la idea de que la mayoría de los empleos ocupados por las mujeres eran una amenaza para sus funciones biológicas, y que el aborto alteraba su fertilidad.

Insistió en que los niños menores de tres años estaban mejor en casa que en las guarderías, y se descubría que el «rol natural de las mujeres en tanto que madres y guardianas de la tierra» era la condición esencial de la creación de calor y de lazos afectivos en el seno de la familia, unidad de base de la sociedad.

En los años 70, la igualdad había sido simplemente redefinida. No se trataba ya de liberar a las mujeres de la educación de sus hijos y de los trabajos de la casa para que ellas pudieran repartir el poder de la clase obrera con los hombres. La igualdad consistía en impedir a una mujer el oponer sus tareas de esposa y madre a su trabajo.

En la mayoría de los países socialistas, las medidas tomadas después del encuentro brutal entre el sueño y la realidad, son ante todo medidas demográficas. Su propósito no está disfrazado. Para dar un ejemplo, he aquí una decisión del Bureau político del Comité Central del Partido Comunista Búlgaro fechada el 6 de marzo de 1973 y presentada a las Naciones Unidas en una nota búlgara sobre el Año Internacional de la Mujer en abril de 1975:

Corresponde a nuestro Partido y a nuestra política de Estado el permitir a las mujeres poder combinar sus principales funciones de manera que se estimule $y$ facilite muy particularmente su rol de madres...

La maternidad es una función social y biológica de la mujer cuya importancia vital para la sociedad reside primero en la complejidad de todas sus funciones. Es la condición primera de su confianza en sí misma y de su felicidad. Nuestra divisa es: Más niños en cada familia búlgara... [las cursivas son del texto originall.

En Checoslovaquia, a finales de los años 60, se dio un paso hacia adelante para ayudar a las mujeres a combinar sus principales funciones: 
comprendía especialmente la puesta al día de una legislación protectora elaborada que prohibía a las mujeres participar en una larga lista de profesiones que podrían no ser compatibles con su función maternal, o que representaran un stress suplementario "con respecto a la doble carga en el seno de la familia y en su trabajo». El Estado atribuyó asignaciones para el segundo, el tercero y el cuarto hijo en las familias que los tuvieron rápidamente, préstamos de bajo interés a las jóvenes parejas con deducción parcial por cada hijo que tuvieran, y una asignación especial que permitiera a la madre quedarse en el hogar con su segundo hijo y con cada uno de los hijos siguientes hasta su segundo año de edad.

Unas medidas similares, e incluso más generosas, fueron tomadas en Hungría. Además, Checoslovaquia y Hungría corrigieron su legislación sobre el aborto en 1973. Checoslovaquia rehúsa el aborto por razones no médicas a las mujeres que no tienen todavía ningún niño: Hungría limita el aborto a las mujeres que como mínimo han tenido tres. Rumania revisa brutalmente su política extremadamente liberal en materia de abortos por un decreto, que se remonta a 1966, que prohíbe el aborto a las mujeres que tienen menos de 4 niños vivos; al mismo tiempo, hacía más difícil la obtención del divorcio y suspendía la importación de contraceptivos.

Las medidas para el sostenimiento de la familia cuestan caro al Estado $y$, teniendo en cuenta las circunstancias, alivian mucho a las jovenes familias. En Checoslovaquia, una obrera del textil que se queda en su casa con su tercer niño hasta el segundo año recibe unas asignaciones equivalentes al $80 \%$ de su salario. Una madre húngara que se queda en su casa con su segundo hijo cuando el primero tiene menos de 3 años, recibe una suma mensual muy superior al salario mensual medio de una obrera.

Estas medidas pueden ser medidas demográficas eficaces pero, a pesar de que son presentadas como tales, no tienen nada que ver con «un acercamiento marxista concreto a la cuestión de la mujer» ni con cualquier promoción de la igualdad, a pesar de la buena voluntad de sus autores. Estas medidas permiten a los hombres socialistas continuar utilizando a las mujeres socialistas en trabajos de rutina mal pagados teniendo al mismo tiempo la comida caliente en la mesa, y recoger los laureles de una reputación de hombres que no sólo han liberado económicamente a las mujeres, sino también han protegido su derecho a la maternidad.

Una cierta atmósfera de glorificación de la maternidad, incluso si no se acompaña de medallas, es de todos modos necesaria para que la presión ejercida sobre las mujeres para que tengan niños tenga sus efectos. 
La familia es el campo reservado de la madre, es donde su función maternal se extiende a todas las tareas que no tienen nada que ver con la biología.

La presión ejercida sobre el gobierno para la creación de guarderías destinadas a los niños de menos de 3 años se relaja; las mujeres que trabajan, y aquellas que no quieren o no pueden permitirse el lujo de quedarse en su casa, tienen muchas dificultades para colocar a sus hijos. Los 100.000 puestos que deberían estar disponibles para este grupo de edades en 1970 en Checoslovaquia no habían sido aún conseguidos a finales de 1975.

Cuando la joven madre vuelve al trabajo al cabo de dos o tres años, por la fuerza, puesto que su derecho a las asignaciones ha expirado, descubre que no ha habido grandes novedades en lo que concierne a servicios, y que su marido no parece estar muy dispuesto a ayudarla en sus tareas domésticas.

Hace poco tiempo una obrera escribía en una revista económica checoslovaca: «La única ocasión en que la obrera tiene una sola jornada de trabajo es cuando tiene la excedencia por maternidad.» $Y$ añadía: «Los hombres dejan casi todo el trabajo familiar a las mujeres. Cuando el marido llega a hacer una cierta cantidad de trabajos domésticos, no los hace nunca como si se tratara de la parte que le corresponde para mantener un mecanismo que le es útil a él también, sino como una ayuda a su mujer.»

Como contribución al Año Internacional de la Mujer, una mujer sociólogo explicaba en un periódico del Partido Comunista Checoslovaco del verano pasado, bajo el título: Socialismo y liberación de las mujeres, que contrariamente a la «ideología burguesa que rinde culto a la madreama de casa» y a partir de este hecho considera que los dos aspectos del rol de las mujeres son incompatibles, el socialismo permite a las mujeres sintetizarlos con éxito.

$Y$ sin embargo, la misma autora había señalado, en otro artículo aparecido en otro periódico tres días antes, que las mujeres checoslovacas ocupaban 4 o 5 horas al día en trabajos domésticos a causa de la falta de servicios, de la ineptitud de la red comercial y de la ausencia de ayuda eficaz en el cuidado de los hogares. Las mujeres asalariadas pasan más tiempo en trabajos domésticos que antes del establecimiento de la semana de 5 horas en 1968, decía. Pueden ahora consagrar su mañana del sábado a los trabajos de rutina.

Una encuesta soviética realizada en Moscú y en Leningrado ha revelado que las mujeres asalariadas pasaban más tiempo haciendo los trabajos domésticos que cuarenta años antes. Según el sociólogo que cita estos he- 
chos, esto sería debido a la actitud de los hombres que se desentienden totalmente de sus mujeres y les dejan dirigir su casa y los asuntos de la familia.

La idea de que la mujer sería un día liberada de sus tareas suplementarias por «la revolución científica y tecnológica» forma parte de la mitología socialista. No hay por el momento ningún síntoma de movilización de los inmensos presupuestos que serían necesarios para conseguir el nivel de posibilidades que tiene Occidente en materia de equipamiento doméstico y de servicios. Al contrario, la Unión Soviética ha renunciado a la prioridad efímera que había concedido a los bienes de consumo en provecho de la industria pesada en su plan de 1976-1980. En Checoslovaquia se ha reconocido ahora que no existe ninguna política global de racionalización de los trabajos domésticos. La tendencia es de proveer el equipamiento de cada hogar, pero no existen servicios de postventa, y los nuevos apartamentos no tienen lugar para las máquinas de lavar. En ciertos inmuebles incluso está prohibido tenerlas.

En cuanto a la mujer que se ha quedado algunos años en casa con sus hijos, vuelve manifiestamente al trabajo con un pesado handicap en relación con el hombre de su misma edad. Además, cualquier patrono que emplea a una mujer en un puesto de responsabilidad corre el riesgo de verla desaparecer de un momento a otro durante dos años o más. ¿Cómo, entonces, ocupar su puesto, ya que éste debe serle reservado? Reacciona pues, como su homólogo capitalista: más vale emplear a un hombre desde el principio.

Las mujeres no pueden ser simultáneamente educadas para llegar a ser ante todo madres y guardianes de su hogar, y al mismo tiempo obligadas a poner la mira sobre empleos poco convencionales que exigen la movilización de cualidades que habían sido abandonadas hasta entonces. Tal como los media de los países socialistas no dejan de señalar, hay más jóvenes en los cursos técnicos de las escuelas socialistas que en los del Occidente capitalista.

Sin embargo, esto es sobre todo debido a la cuota atribuida por diferentes tipos de escuelas en su esfuerzo de dar una respuesta a las necesidades de la economía, y no a una manifestación mayoritaria de las preferencias de las mujeres.

Cuando pueden escoger, las jóvenes optan en una mayoría aplastante, por las profesiones tradicionales. La política del empleo coincide en mantener la división en el mercado del trabajo y se tiene continuamente tendencia a emplear a las mujeres en el «sector no productivo» -los servicios- donde representan ya una aplastante mayoría de mano de obra. Al mismo tiempo, algunas industrias están dominadas por las mujeres y 
otras, como la administración civil, tiene necesidad de aumentar el número de mujeres. $\mathrm{Y}$ se continúa así insistiendo en el lugar que corresponde a las mujeres en la tecnología deplorando al mismo tiempo su falta de interés en este campo.

En Checoslovaquia, durante estos diez últimos años, el número de jóvenes sobre el conjunto de adolescentes aprendices en el comercio y la industria ha disminuido del 36 al $30 \%$ del total. Entre ellas, el $80 \%$ han sido formadas en las industrias femeninas tradicionales y en los servicios. Las escuelas de aprendizaje no están abiertas de manera igual a los chicos y a las chicas. En la administración civil, las chicas representan menos del $5 \%$ de los aprendices. En 1973, las jóvenes sólo ocuparon del 10 al $15 \%$ de los lugares reservados a mujeres aprendices de mecánica (mecánicos torneros o fresadores), y el tercio de las posibilidades que les ofrecían como aprendizas en el textil. Pero había 9 demandas por cada puesto en el aprendizaje de la bisutería, y 8 por cada oferta de aprendizaje para la venta al detalle.

En el curso de este mismo período, el número de chicas aumenta en las escuelas profesionales pero disminuye en la rama industrial de las escuelas. Las chicas representan el $90 \%$ de los alumnos que se preparan para ser enfermeras, profesores, bibliotecarias o secretarias. En la universidad, se descubre la misma tendencia de retracción en las carreras técnicas. Las mujeres escogen en su inmensa mayoría las humanidades, la economía y la medicina. Son también los campos que ofrecen más posibilidades a las mujeres, ya que los hombres se inclinan por otras materias.

Numerosas encuestas muestran que la división del empleo entre los oficios de hombres y los oficios de mujeres son ya una mera habitud. Si la justificación socio-económica original ha desaparecido, la idea no queda menos profundamente enraizada en la psicología de la sociedad. La legislación protectora supuestamente destinada a ayudar a las mujeres débiles, protege en realidad los privilegios de los hombres. Como lo ha dicho la sociólogo polaca Magdelena Sokolowska:

Cuando las mujeres trabajaban en las fábricas y en el campo, nadie se preocupaba de ellas. Desde que comienzan a especializarse y a reclamar un salario igual por un trabajo igual, los hombres se empiezan a preocupar de su salud, de sus nervios.

Entre las «profesiones típicamente femeninas» muchas de ellas son difíciles y monótonas, y producen enfermedades profesionales especificas. Ciertos trabajos masculinos podrían ser adaptados a las mujeres, ya que éstas forman ahora una mano de obra importante y estable. Ocurre a 
menudo que la legislación protectora no puede ser aplicada, incluso en los «empleos convenientes para las mujeres». Por ejemplo, es imposible prohibir el trabajo de noche a las mujeres en los servicios de sanidad y en las comunicaciones, ya que representan una mayoría aplastante de empleadas.

En las tiendas de venta al detalle checoslovacas, de las cuales el $80 \%$ de empleados son mujeres, es todavía imposible aplicar diez años más tarde la prohibición emitida en 1967 de levantar cargas pesadas. En 1970, más de medio millón de mujeres levantaban regularmente unas cargas más pesadas que las autorizadas por la ley. Cuatro años más tarde, todavía había 425.000. En 1975, el ministerio de Industria eslovaco anunció que el fracaso de la aplicación de la legislación protectora era general, y que más de 15.000 mujeres trabajaban en profesiones consideradas como peligrosas.

Así, la legislación protectora elimina pura y simplemente la necesidad de reservar para las mujeres ciertas profesiones donde los hombres no tienen la costumbre de verlas. La medida de sinceridad de esta sociedad puede ser tomada en el hecho que nadie haya sugerido una legislación que evite a las mujeres el trabajar de 12 o 13 horas por día que efectían en su mayoría, a pesar de que las encuestas hayan mostrado, por ejemplo, que el $45 \%$ de las mujeres checoslovacas asalariadas se quejan de fatiga crónica.

La legislación protege los beneficios de los hombres.

Se puede encontrar un ejemplo sorprendente en la agricultura checoslovaca, donde la mayoría de los cultivos no mecanizados y de las cosechas a pesar de ser físicamente insoportables, han sido siempre efectuados por las mujeres. Hoy día son reemplazadas por los conductores de tractores y de las máquinas agrícolas - los hombres. Se considera que estos trabajos no son sanos para las mujeres. Los salarios de los hombres que las han sustituido son exactamente el doble de los que tenían las mujeres reemplazadas.

En toda Checoslovaquia, el salario medio de las profesiones dominadas por los hombres es superior a la media nacional: en las profesiones dominadas por las mujeres, es inferior. En 1973, el $72 \%$ de las mujeres que trabajaban fuera del sector agrícola ganaban un salario inferior a la media nacional, contra el $31 \%$ del de los hombres. En la misma época, el $4 \%$ de las mujeres que trabajaban ganaban el SMIG, ${ }^{*}$ mientras que los hombres que ganaban como mínimo el SMIG representaban una cuarta parte de esta cifra. Esta diferencia de salarios es típica de todos los países industrializados, sean del Este o del Oeste. En tales circunstancias, la ex-

* Salario Mínimo Interprofesional Garantizado. 
presión «a trabajo igual, salario igual» no tiene realmente ningún sentido; las mujeres no tienen generalmente un trabajo igual.

Una de las consecuencias poco habituales de la concepción socialista de la igualdad «a dos caras» de las mujeres, es que las mujeres empiezan a aparecer en los puestos de dirección, incluso en las industrias donde representan la mayoría de los trabajadores. Es un hecho que se señala frecuentemente en la prensa socialista. No hace mucho tiempo, una periodista checoslovaca dio cuenta de una conferencia sobre los problemas de la mano de obra, donde todos los participantes, que eran hombres, pidieron que se reclutara a chicos jóvenes para formarlos y destinarlos a los puestos de dirección. Cuando ella les preguntó individualmente si pensaban que una mujer podía hacer una función de dirección, sólo recibió una respuesta afirmativa franca. Los otros se hacían eco de las objeciones habituales: las mujeres dirigentes «pierden su feminidad», "prefieren su familia al trabajo», son «gobernadas por sus emociones», en cambio un hombre hábil puede «hacer lo que quiera», ellas sin embargo «no tienen el sentido de las decisiones que se deban tomar», «las mujeres incluso rehúsan las responsabilidades». Sin embargo, cuando la misma periodista entrevistó a los colegas femeninos de estos hombres cuya promoción hubiesen podido prever, todas, excepto una, afirmaron que las mujeres estaban capacitadas a ocupar los puestos de trabajo directivos, pero que los prejuicios masculinos y las responsabilidades domésticas eran los dos grandes obstáculos a esta promoción.

Los prejuicios son duros de pelar y todo cambio necesita tiempo. Sin embargo, vale la pena señalar que en las sociedades donde los esfuerzos ideológicos son conscientemente inclinados hacia el cambio, donde una campaña de masa puede ser organizada en una noche, donde sería suficiente una sola elección para que el número de mujeres empleadas para hacer funcionar un sindicato local de comerciantes sea, bajo la dirección del Partido, significativamente crecido, no ha habido ni la menor sospecha de campaña para convencer a los hombres que tenían que repartir con las mujeres las tareas domésticas. Se remite, púdicamente, en cuanto a esto, al desarrollo espontáneo de la moral socialista.

Incluso, a pesar de que ha habido muchas proclamaciones de buena voluntad, no ha habido ni una sola campaña para reclutar, entre las numerosas mujeres que han adquirido una experiencia en el curso de los años pasados, aquellas que serían susceptibles de ocupar los puestos de dirección y de gobierno. De hecho, ninguna campaña ha sido jamás declarada contra los prejuicios masculinos, donde se reconozca, sin embargo, que son un obstáculo para el camino del progreso.

La razón es simple: las campañas son organizadas por los hombres. 
El antifeminismo del proletariado que se dirigió con tanto éxito contra las militantes del movimiento de las mujeres cuando la II Internacional y sobrevive actualmente en los partidos socialdemócratas de la Europa occidental, no es menos sólido en la Europa del Este.

Allí, la sociólogo polaca Magdelena Sokolowska ofrece una explicación en una declaración hecha en el simposio sobre la mujer socialista, en Salzburg (Austria) en 1970:

Las sociedades de la Europa del Este son sociedades de predominio campesino. Las relaciones entre los habitantes de las zonas urbanas y los de las zonas rurales son todavía muy fuertes. Los líderes políticos son en su mayoría de origen campesino o bien obrero. ¿Quizás, en materia de rol femenino, estos hombres creen todavía en los estereotipos encarnados por sus propias madres?

Se puede encontrar siempre una excepción a este estado de hecho en la República Democrática Alemana, donde la falta de técnicos expertos ha obligado al gobierno a dar las directrices para que cada empresa prevea la formación de mujeres en los campos de la tecnología y de la dirección. Además, no se considera en la Alemania del Este que la conducción de camiones, tractores o de máquinas de segar pueda ser peligrosa para las mujeres.

Se llegó a esta conclusión al ver lo mucho que había descendido la población en edad de trabajar en la RDA: llegó a disminuir en un $15 \%$ entre 1950 y 1973 , pasando de 11,7 millones a 9,9 millones. A pesar de que la Alemania del Este comparte con la República Federal Alemana el privilegio de tener la tasa de natalidad más baja del mundo, obligada a escoger entre la fuerza de trabajo del presente y la del futuro, la RDA optó por la del presente. Recomendó, pues, a las mujeres que siguieran trabajando, y no precisamente en casa, autorizando el aborto y ofreciendo la mejor organización de guarderías de todos los países. Es interesante remarcar que sus competidores inmediatos en lo que concierne a guarderías de niños de edad preescolar, no son los estados socialistas, sino Francia, Bélgica e Istael.

La RDA tiene también la particularidad de haber producido la primera novela política de una mujer socialista, The Life and Adventures of Trobadora Beatriz, de Irmtraud Margner, que explica la cólera de una mujer contra la «igualdad de derechos» que, de hecho, la autoriza a hacer el trabajo de un hombre además de su trabajo de mujer. Como la Unión Soviética, Alemania del Este ha llegado a ser un caso particular, incluso en 
el seno del bloque del Este, al cual sin embargo le falta mano de obra. Las mujeres tienen las mismas posibilidades de obtener empleos de responsabilidad, porque hay menos hombres para reclamarlos. Sin embargo, no es más avanzada que los otros países socialistas en lo que concierne a la supresión de la segunda jornada de trabajo para las mujeres. Se estima que el trabajo de una obrera que tiene dos niños llega a las 50 horas semanales.

El modelo de liberación de las mujeres propuesto generalmente por el socialismo se contenta sólo en institucionalizar el modelo familiar de los «dos roles de una mujer», que es también el modelo dominante en todos los países de la Europa Occidental, donde el empleo de las mujeres no ha alcanzado todavía el nivel del de la Europa del Este, pero, sin embargo, el vacío se va llenando cada día más. Este modelo se basa sobre una presunción popular según la cual las mujeres y los hombres serían iguales pero diferentes, y que deberían ser las mujeres las que cambiaran sus normas. Las mujeres cumplen dos funciones, los hombres una sola. Las dos funciones de las mujeres valen mucho menos que la función única del hombre; ocupan más tiempo, pero son peor remuneradas.

Se puede comprobar que los países socialistas y capitalistas difieren muy poco en cuanto a su visión oficial del lugar que corresponde a las mujeres en la sociedad, examinando dos enmiendas introducidas una por la Unión Soviética y la otra por el Japón, en el proyecto de plan de acción internacional propuesto en 1975 en Méjico, cuando se organizó la conferencia de las Naciones Unidas para el Año Internacional de la Mujer, enmiendas cuyos términos son casi idénticos.

Las dos estaban destinadas a ser colocadas a continuación de la primera frase del párrafo 16 que declara: «La realización de la igualdad entre las mujeres y los hombres implica que las dos partes tengan en igualdad de derechos, unas posibilidades y unas responsabilidades que les permitan cultivar sus capacidades mentales individuales en beneficio de su realización personal y en beneficio de la sociedad.»

La Unión Soviética propone que se añadan estas palabras: «El Estado y la sociedad deben crear las condiciones que permitan a las mujeres combinar con éxito sus deberes de madres, de trabajadoras y de ciudadanas.»

El Japón propone esta versión: «Deberán hacerse los arreglos que sean necesarios para permitir a las mujeres que tengan responsabilidades familiares el poder conciliar su doble responsabilidad, tanto en el seno de la familia como en las actividades exteriores del hogar.»

Estas dos proposiciones están en conflicto con el sentido del párzafo adoptado, el cual no habla de doble responsabilidad de las mujeres, sino 
de la responsabilidad común de hombres y mujeres de cara al hogar y al cuidado de los niños.

Ha sido pues probado que las mujeres podían ser adscritas por la fuerza del trabajo hasta el punto de representar el $15 \%$, prepararse para las profesiones hasta entonces consideradas como típicamente masculinas, y esto durante 50 años o más, sin que ello represente una división de los roles en el seno de la familia, o un cambio en la manera en que los hombres y las mujeres ven estos roles y el conjunto de las relaciones entre hombres y mujeres.

Es una primera conclusión. La segunda es que el hecho necesario de insistir sobre la democratización económica y política como condición de la emancipación total de las mujeres, no debe impedir poder ver que, a pesar de que los poderes políticos y económicos y el poder machista coinciden, no son exactamente lo mismo.

No es sorprendente constatar que el análisis marxista tradicional de la condición de las mujeres no ha concedido ninguna importancia al hecho de que la sociedad socialista hereda de la sociedad capitalista una estructura y una multiplicidad de instituciones creadas por los hombres en un sistema de valores masculino. La idea de un sistema económico diferente puede ser aceptada, pero los fines y las prioridades machistas se confunden siempre con los fines y prioridades de la humanidad, tanto para las mujeres como para los hombres.

$\mathrm{Y}$ sin embargo la sociedad que los socialistas habían previsto al principio y que la mayoría de los partidarios de la liberación de la mujer han previsto hoy - en la cual todas las mujeres capacitadas se encontraran fuera del hogar con las mismas condiciones que los hombres mientras que las tareas domésticas y el cuidado de los niños llegaran a ser una responsabilidad colectiva - esta sociedad exige que se reconsideren las prioridades en función de un sistema de valores diferente.

Esto implica la revaluación de todas las tareas que los hombres y las mujeres llevan a cabo generalmente, según el sistema de valores diferentes, y conduce inevitablemente a transformar no sólo el modo de vida de las mujeres, sino también el de los hombres. Se trata de transformar la visión que se tiene de lo que es masculino y de lo que es femenino; no de contentarse en comprender los problemas del otro sexo, sino de hacer el esfuerzo consciente para acceder a las características válidas adquiridas por el otro sexo en su experiencia del rol que le ha sido asignado por la sociedad. Actualmente, cada sexo sólo utiliza la mitad de sus recursos potenciales.

Ha sido idea de algunas mujeres, como Sokolowska, el que las tareas de dirección podrían ser organizadas para ser ocupadas por hombres y 
mujeres que no quieran consagrar toda su vida a su profesión. $O$ incluso una visión del mundo donde los caracteres «femeninos» tuvieran un rol importante en el momento de tomar una decisión.

Sea como sea, la idea relativamente nueva según la cual los hombres y las mujeres podrían repartirse por igual el trabajo del mundo y los cuidados de la familia, y que esto pudiera ser incluso una cosa positiva tanto para los hombres como para las mujeres, esta idea tiene pocas posibilidades de ser apoyada en una gran parte del globo donde las nuevas ideas y el libre intercambio de opiniones no son muy bien acogidos.

El aislamiento de las mujeres (y de los hombres) socialistas ha creado un defecto de comunicación. De un lado, las mujeres de la Europa del Este sienten una gran ilusión respecto a como viven las mujeres del Oeste. De otro, no tienen ninguna información sobre la revolución que ha tenido lugar entre las mujeres de Occidente en el curso de estos últimos diez años, sino es a través de noticias que les llegan doblemente infiltradas, deformadas por los media de Occidente y por su propia prensa. Las mujeres socialistas comprometidas en el estudio de los problemas de las mujeres no tienen tampoco ninguna noción de las investigaciones importantes que han sido hechas a la vez por hombres y mujeres en el campo de los estudios feministas estos últimos años, estudios que revelan hasta qué punto la inegalidad opera a niveles de realidad y de conciencia diferentes y que ambos deben ser atacados.

El segundo de estos factores que han obrado contra la transformación real de los roles sexuales en los países socialistas de Europa, es la relativa fuerza y la importancia de la familia tradicional en Europa central y en la Europa del Este. A través de lo que era antes Rusia, Prusia y el imperio Austrohúngaro, aflora la influencia de las costumbres rurales, de la Iglesia y la huella poderosa de la monarquía feudal.

En los pequeños paises que sólo han llegado a ser Estados independientes después de la Primera Guerra Mundial, la familia ha jugado, además, el rol de guardián de la lengua y de la cultura nacionales, función que en las sociedades más modernas ha sido largo tiempo confiada a las instituciones públicas impersonales. A través de esta herencia que comparten, las mujeres de la Europa central socialistas y no socialistas tienen más cosas en común entre ellas que con las mujeres de Francia, Gran Bretaña, Estados Unidos o de los países escandinavos, donde las posibilidades, y de hecho la necesidad, que tiene un individuo de actuar sobre su propio destino tiene una considerable tradición histórica.

En los países socialistas hay muchas mujeres que se dan cuenta del hecho que están manipuladas, pero pocas saben de qué manera lo están. Piensan que sus derechos jurídicos, su trabajo fuera del hogar y la inde- 
pendencia que esto les confiere son cosas ya adquiridas. Su profesión amplía su horizonte y les da una nueva autoridad sobre el hogar. En la mayoría de los países tienen libertad para pedir el divorcio. No están ya atadas por lazos familiares arcaicos que las subordinan a sus maridos, como aún sucede en Alemania Federal en el momento en que esto se redacta.

Sin embargo, esto no las ha conducido a poner en cuestión la manera por la cual la familia continúa funcionando y perpetuando las ventajas de los hombres. Al contrario, la familia aparece a menudo como un refugio personal, y las responsabilidades familiares llegan a ser una forma de escapar a «la emancipación» obligatoria. En este conflicto entre su profesión, donde tiene que competir con los hombres en su propio terreno, y su casa, donde es «irremplazable», la mujer escoge casi de una manera natural su rol familiar, que nunca le es rehusado. Es quizá porque todavía no ha disfrutado de los privilegios que la sociedad de consumo confiere a las mujeres de Occidente, el por qué acepta creer que con ellos vendrá la igualdad.

Si el chovinismo masculino y la colaboración femenina que lo mantiene no se pueden resolver por la democracia económica y la mejora de los bienes de consumo, ya es hora que cada individuo, hombre o mujer, saque conclusiones personales y cese de practicar el milenarismo socialista... un pensamiento fálico. El que conozca la fuerza del deseo sueco de combinar a la vez libertad individual y responsabilidad personal, no se sorprenderá de saber que Suecia es el primer país en haber hecho oficialmente a la comunidad responsable del rompimiento de las actitudes tradicionales y de la transformación de los roles jugados tanto por los hombres como por las mujeres.

Para explicar el por qué Suecia ha llegado a un equilibrio en el cambio social pacífico, se invoca a menudo la combinación favorable de más de un siglo de neutralidad ininterrumpido por los conflictos mundiales y de una reserva inagotable de recursos naturales. Además, ni el feudalismo ni el catolicismo han logrado implantarse realmente en Suecia. La industrialización se ha logrado bastante tarde y bastante rápidamente, sin la creación de un proletariado urbano importante y claramente definido, si bien las ideas socialdemóctatas, que estaban ya en su apogeo en el resto de Europa, fueron modificadas para aplicarse a una base más extensa. Esto dio como resultado la línea ante todo pragmática que sigue todavía hoy el partido socialdemócrata sueco, el cual no ve ninguna razón para no preconizarla. La obligación marxista original de nacionalizar los medios de pro- 
ducción fue abandonada en provecho de una tentativa de crear una sociedad más justa partiendo "del lado malo», es decir, socializando más bien el consumo que las industrias-clave y las finanzas, tentativa específicamente sueca.

Utilizando lo mejor posible sus ventajas, el partido socialdemócrata ha llegado a mantenerse en el poder más de cuarenta años, habiendo reparado los servicios públicos y sociales desiguales, sin tener por ello que echar por tierra el big business.

Todo esto tiene una incidencia particular sobre la igualdad de las mujeres. Los reformadores suecos aprendieron muy pronto a pensar en términos de programas sociales globales más que en medidas individuales para cubrir el expediente. Así, la mayoría de las medidas radicales concernientes a la seguridad social y a la ayuda pública, creadas en los años 30 al estilo sueco de los «medios insuficientes», fueron generalmente aceptadas porque fueron presentadas como formando parte de un conjunto de medidas destinadas a terminar con la depresión económica y el debilitamiento de la población. También el programa de igualdad de los roles sexuales ha sido aceptado como formando parte de un programa de igualdad adoptado por el partido socialdemócrata en 1968 y no solamente por las mujeres sino también por los jóvenes, los viejos, y los disminuidos sociales y físicos.

Su exasperante ausencia de ortodoxia, su conservadurismo en relación a la revolución, y sus concesiones al sistema del provecho han hecho que la solución sueca, $\tan$ eficaz en el mejoramiento de los standards de vida, aparezca como poco seductora tanto para la Vieja Izquierda como para la Nueva Izquierda. Por estas mismas razones, las feministas radicales evitan los peregrinajes para extraer alguna lección de un estado de hecho sueco, a pesar de que recientemente ha llegado a ser un terreno privilegiado de los estudios de las diferentes formas de androginia - una división muy igualitaria de los roles y de las cualidades humanas entre hombres y mujeresque, para muchos de ellos, es una de las características esenciales de una mejor sociedad futura.

He sido sin embargo sorprendida por la ironía que representa el hecho de ver a las feministas, que en otros países habrían pertenecido a grupos de liberación marginales y hubiesen apelado a soluciones estereotipadas, sentándose en Suecia en los despachos gubernamentales para aplicar los programas sobre la igualdad de sexos. El acceso que tienen a ello, insistiendo con decisión sobre la independencia económica de la mujer más que sobre la «libertad de escoger», representa una amenaza para muchos hombres y mujeres suecas que esperaban, como en los buenos tiempos, que la igualdad podría producirse sin demasiados cambios. 
No se discute la legislación especial de protección de las mujeres, ya que, en principio, Suecia está en contra. Las nuevas leyes sobre la familia hacen que los hombres y las mujeres lleguen a ser compañeros iguales, y otra legislación elimina las diferencias durante mucho tiempo aceptadas entre los hombres y las mujeres a nivel de los impuestos y de la seguridad social. Las diferencias de impuestos entre hombres y mujeres, entre individuos casados o solteros, las pensiones alimentarias o de viudez, son o serán suprimidas, eliminando al mismo tiempo el concepto del hombre protector. Por otra parte, los derechos del hombre en tanto que padre han sido incrementados. Puede, en adelante, quedarse en casa con un recién nacido o con un niño enfermo, y cobrar las asignaciones con el mismo derecho que la madre.

En enero de 1974, la introducción de la noción de «asignación familiar» destinada a reemplazar la asignación de la maternidad, permiten a uno y a otro cónyuge el utilizar todo el período o una parte de él de los ciento ochenta días que tienen para cuidar del recién nacido cobrando el $90 \%$ de su salario. Lo que no significa, sin embargo, que los padres suecos puedan cobrar asignaciones para pasar varios años con un niño. He descubierto con gran regocijo que esta propuesta, considerada como una solución «socialista» en la Europa del Este, era en Suecia una reivindicación del partido conservador. Los partidarios del gobierno reclaman por su parte muchas más guarderías de buena calidad, solución ciertamente más cara pero que representa, según ellos, la única manera de acceder a una igualdad práctica. El gobierno prevé cubrir la solicitud de plazas hacia 1985, a pesar de que el comienzo del programa ha sido un poco lento.

La nueva ley sobre la familia refuerza el derecho del padre para obtener la custodia del niño en caso de divorcio, o de separación si el niño ha nacido fuera del matrimonio. Se me ha dicho que las próximas transformaciones de la ley repercutirían sobre la protección de los miembros de un mismo hogar, estén o no casados, miembros del mismo sexo o que vivan en comunidad.

Las necesidades de mano de obra han puesto fin al debate sobre el «rol sexual» que estaba en pleno apogeo cuando aparecieron las medidas innovadoras de los años 70. A pesar de no haber alcanzado las cifras de la Europa del Este, el empleo de las mujeres en Suecia está en uno de los más altos niveles de Occidente: las mujeres representan el $41 \%$ de la fuerza de trabajo y el $57 \%$ del conjunto de mujeres que tienen un niño en edad preescolar, trabajan. Sin embargo, el $40 \%$ de las mujeres suecas se conforman en trabajar media jornada, a pesar de que la renta anual media de las mujeres es más elevada que la de los hombres. Los bajos salarios han sido recientemente reajustados, con prioridad con la categoría 
obrera, y así el salario medio por hora de las mujeres ha sido elevado al $86 \%$ del de los hombres; esto queda sin efecto en la medida que la mayoría de las mujeres trabajan la media jornada, y que el $80 \%$ de las mujeres se reparten entre once profesiones típicamente «femeninas».

En consecuencia, los primeros esfuerzos del Consejo consultivo sobre la igualdad entre hombres y mujeres dirigidos al primer ministro, consejo recientemente creado, se han llevado a cabo contra la propia barrera de las profesiones. Ha sido con su permiso, por ejemplo, que el departamento del Mercado del Trabajo gubernamental ha lanzado un proyecto-piloto de tres años de duración elaborado con el concurso de ciento cincuenta empresas. Unas «jornadas de información» han tenido lugar en regiones donde el trabajo de las mujeres representa poco, pero donde las industrias típicamente masculinas están buscando obreros.

Vienen luego los cursos de formación para aquellas que están interesadas, y una vez terminados, las mujeres obtienen la autorización para ensayar tantas profesiones como quieran hasta que encuentren una que les convenga. Esta medida elimina la objeción clásica: ¿Y si esto no me gusta? $\mathrm{Y}$ el hecho de que las mujeres acepten en grupo un empleo significa que no tendrán que afrontar solas un medio ambiente hostil. $\mathrm{El}$ sindicato ha organizado debates en las empresas para abrirles un camino y para que sean aceptadas por los hombres.

Por supuesto, no es porque cambia las costumbres de empleo de las mujeres entre las masas por lo que este proyecto es válido. Se trata simplemente de abrir un enclave y no se sabe aún claramente en qué medida el mercado del trabajo quedará abierto. Algunas fábricas consideran este proyecto como una experiencia positiva y están de acuerdo en continuar empleando a mujeres y a facilitarles sus mejoras. Además, el proyecto habrá permitido como mínimo poner al día los factores sobre los cuales descansa el statu quo. En un pequeño astillero que he visitado, donde seis mujeres soldadoras habían sido contratadas, los representantes del sindicato y los de la dirección se pusieron de acuerdo para decir que eran buenas obreras, pero que no creían que pudiesen ser empleadas en otros trabajos del astillero. Al insistir yo para saber porqué, lo único que fueron capaces de decir fue que «quizá pudiese desmejorar su apariencia».

Las chicas mismas entraron en la discusión y declararon que estaban preparadas para hacer cualquier trabajo que les fuese pedido. Reconocieron, sin embargo, que dejarían probablemente el trabajo el día en que tuvieran niños; las dos cosas a la vez era demasiado, incluso si su marido se repartiera con ellas los cuidados de la casa - cosa que esperaban que sucediera.

Las mujeres mayores tienen otras reservas. Aparte de las mujeres 
que son el único sostén de su familia, aquellas que han sido colocadas por este programa se contentan en mejorar la renta familiar, pero no tienen mucha necesidad de trabajar. Les falta encontrar su propio estímulo. La sociólogo Rita Liljeström, en el curso de una encuesta detallada efectuada sobre treinta de estas familias, descubrió que la mayoría de las mujeres se tenían en poca estima y no ocupaban un empleo especializado. La mala opinión que tenían de las otras mujeres se unía a la de los grupos de dominación masculina. Les gusta trabajar y comparan su vida actual al aislamiento que la había precedido, pero es bastante improbable el que hubiesen dado el primer paso por sí mismas. Descubren por primera vez lo que hubiera podido ser su vida si ellas hubieran dejado pasivamente que las circunstancias se adueñaran de sus destinos.

Por otra parte, sus maridos han sido «programados para el trabajo» y se consideran ante todo como padres protectores. A pesar de que algunos ayudan en la casa, la mayoría están demasiado cansados después de ocho horas de duro trabajo. Tienen dificultades para establecer contacto con sus hijos.

Algunos representantes de ciertas empresas a quienes se preguntó cuál sería su actitud si un empleado les anunciaba que quería aprovecharse de su derecho de quedarse en su casa con un recién nacido, examinaron la situación con una cierta inquietud y subrayaron la dificultad en conservar una reserva de mano de obra cualificada. Los hombres mismos aceptaron la idea en principio, pero no veían muy claro cómo se podría llevar a la práctica. Es una actitud muy extendida, confirmada por el hecho de que a escala nacional sólo el $1 \%$ de los padres pudiendo acceder a este derecho se aprovechan de él; para la mayoría de ellos, la presión de los empresarios, de los compañeros de trabajo y los comentarios de los vecinos representan demasiados obstáculos.

A pesar de que la experiencia sueca haya demostrado manifiestamente que es posible en un país industrialmente avanzado introducir las condiciones legales y sociales de igualdad de las mujeres en una economía basada en la libre empresa, confirma la experiencia socialista en el hecho de que se trata sólo de una trampa para conseguir la igualdad. Pero para llegar al final hay que pasar por un laborioso proceso de transformación de las ideas de la gente.

El hecho de que el apoyo más activo para la igualdad de los roles sexuales provenga oficialmente de los sindicatos -que dependen habitualmente de la supremacía masculina-, es en sí bastante impresionante. Según su propia expresión, su punto de mira es «afirmar el derecho de las mujeres a trabajar y el derecho de los hombres a ser humanos».

Las dos confederaciones sindicales han puesto en el programa de sus 
cursos de formación de militantes sindicales una formación para la igualdad de los roles sexuales o, como ellos mismos la llaman, la «política familiar». Una de las primeras reivindicaciones es la jornada de seis horas, a fin de permitir a los padres poder pasar más tiempo con sus hijos, y reducir también las nueve o más horas por día que la mayoría de los niños pasan actualmente en las guarderías.

Es una experiencia nueva y original oír a un grupo de jóvenes trabajadores discutir en una escuela sindical de lo que significa realmente el reparto del trabajo doméstico y preguntarse si la reparación de un coche puede reemplazar el pasar el aspirador por la casa. Es reconfortante saber que un obrero ha cambiado de vivienda para estar más cerca del sitio donde trabaja su mujer, a pesar de que para él pueda significar muchos problemas. Se preocupan de señalar, sin embargo, que no son «ejemplares» y que faltan todavía unos buenos diez años para obtener la jornada de seis horas, y que de hecho la mayoría de los trabajadores preferirían un aumento de salario y un aumento de sus días de vacaciones.

Es evidente, oyéndoles hablar, que el cambio ha empezado entre los jóvenes. Una educación igualitaria, la búsqueda intensa de vocaciones y el hecho de haber eliminado de los libros de clase los estereotipos sexuales, todo ello ha transformado la costumbre que tenían las jóvenes de considerar el matrimonio como una cartera, pero no ha cambiado la posibilidad de escoger una profesión o el hacer estudios superiores, al menos no de una manera estadísticamente significativa. Tales son los resultados de un «proyecto sobre los roles sexuales» puesto en marcha durante cinco años por el Ministerio Nacional de Educación. Las jóvenes reciben la influencia de lo que sus padres desean, las posibilidades de trabajo que encuentran a su alrededor, pero también del conjunto del proceso de socialización desde su infancia. Según la directora del proyecto la escuela debe trabajar más estrechamente con los padres y la comunidad. Y, añadió, debe transformar su propia imagen: los hombres y las mujeres deben ser representados en igualdad de condiciones en todos los estamentos de la escuela y en todos los niveles de la enseñanza.

En su conclusión, recomienda también que se enseñe más sistemáticamente la tecnología, la economía doméstica y la puericultura a los dos sexos; insistiendo en el «tema no tradicional» de cada sexo para terminar con el handicap que ha representado para cada uno la educación en un solo sentido. También propone que la educación física sea mixta, que haya discusiones sobre la manera como deben aprenderse los roles sexuales y de cómo se manifiestan casi de una manera natural en la mayoría de los cursos de las escuelas, y finalmente pide que una profesión «no tradicional» sea efectivamente practicada en el cuadro de la orientación profesional. 
Para remontar más todavía hasta el origen de los roles sexuales y hasta el momento en que han sido interiorizados por el niño en la conciencia de su propia sexualidad, las guarderías de edad preescolar representan en Suecia una de las reivindicaciones más importantes, apoyada por las jóvenes familias que presionan a los municipios para obtener más plazas todavía. El decreto de 1973 sobre la actividad preescolar no se contenta en hacer de las guarderías una ayuda para los padres, sino que las define como parte integrante del medio ambiente necesario para el feliz desarrollo del niño, así como para que empiece a entender la igualdad de los sexos. El hecho de que haya en las guarderías tantos educadores como educadoras (casi impensable en la Europa del Este) da a los niños la sensación de que los hombres tienen también una función como cuidadores. Los grupos de edades diferentes dan tanto a los niños como a las niñas la posibilidad de cuidar a los más pequeños. La introducción a los misterios de la cocina y el hecho de liberar a las inevitables cocineras y mujeres de limpieza del rol invisible de esclavas al de miembros del personal debería contribuir a una nueva evaluación de estas profesiones «menores».

No es fácil la aceptación de este plan de escuelas modelo por parte del sistema nacional de guarderías. El hecho del aumento de los salarios ha atraído a los hombres a las guarderías, pero sólo representan todavía el $5 \%$ del conjunto total. «Yo no sé cuánto tiempo voy a resistir», dice un joven maestro de guardería. Es la profesión que quiere hacer, pero sus padres y sus amigos no paran de decirle: «¿Por qué no te dedicas a una auténtica profesión?»

Este intenso esfuerzo para crear una atmósfera diferente en Suecia es aún muy reciente, pero se ve claramente el camino largo y difícil que tendrá que recorrer. Un nuevo proyecto gubernamental intenta combatir la mala voluntad de los padres hacia sus nuevos derechos: destinado a ponerse en marcha en 1977, propone la extensión de la «vacación familiar» por un recién nacido de siete a ocho meses a condición de que al menos durante un mes se encargue de él uno de los dos padres que no haya hecho los siete restantes. Otra proposición ofrece a los padres que reducen voluntariamente su tiempo de trabajo a seis horas el compensar la pérdida de dinero por un seguro social. Esta asignación sería pagada durante veinte meses después de la expiración de los ocho meses de vacación familiar, con la esperanza de que cada padre tome diez meses. Esta sugestión reconoce el hecho de que el tiempo en la guardería es demasiado largo, y que incluso con parvularios, el llegar a combinar los cuidados que se dan a los niños con una profesión a tiempo completo es un trabajo agotador para los padres.

Una tal combinación de obligaciones prácticas y de privilegios acabará 
por alcanzar su meta, ¿o la sociedad tendrá que investigar más profundamente en la formación de cada persona, buscar las causas psicosexuales del comportamiento de los hombres y de las mujeres, los miedos y las dudas que no llegan a confesarse? En Suecia, algunas jóvenes feministas piensan que estos obstáculos a la igualdad han sido subestimados hasta hoy por parte de los suecos.

Otra cuestión evidente que se plantea es la de saber si los nuevos valores que crearían una igualdad de roles sexuales son compatibles con una sociedad comprometida en la carrera del PNB maximal y decidida a conservar la nación en su puesto dentro del mercado mundial competitivo. Entre las personas que se han comprometido en la carrera de la igualdad de los roles sexuales en Suecia y en otros países escandinavos, muchos piensan que no.

Ya en 1970, el primer ministro sueco, Olaf Palmer, declaraba ante el público americano: «El nuevo rol del hombre implica que sepa reducir su participación en el mundo del trabajo, y quizá también en la política, durante todo el tiempo en que los niños son pequeños.» Añadió que la pérdida de producción sería compensada por un aumento de la participación de las mujeres.

Pero las cosas no son tan simples. Como lo señalaba uno de los teóricos de la igualdad escandinava de los roles sexuales, la sociólogo noruega Harriet Holter, el sistema económico de la Europa Occidental tiene necesidad de una mano de obra fácilmente reemplazable, flexible y movible, así como de una élite de administradores y de dirigentes capacitados. Sin embargo, la abolición de la diferencia de sexos, el hombre y la esposa trabajando realmente sobre unas bases reales, atacaría de manera considerable la movilidad y la flexibilidad de la fuerza de trabajo. Escribe (en su libro Sex Roles and Social Structure):

Una eliminación de los roles sexuales que conduciría a los hombres a identificarse con los niños y a simplificar sus necesidades sería todavía más contradictorio con los intereses económicos prevalentes. En el sistema sexual, los hombres concilian el trabajo con la vida familiar de manera que repercuta lo menos posible en el sistema profesional... El rol tradicional de las mujeres en la familia es la condición primera para que los hombres puedan comprometerse enteramente en su trabajo, por otra parte a menudo alienante.

En Suecia, Rita Liljeström es de la misma opinión. En su estudio del programa piloto encargado de reducir la segregación profesional, programa 
del cual hemos hablado más arriba, subraya que la meta de la igualdad no es crear mujeres burocratizadas, forzadas a la competición, eficaces y emocionalmente tan pobres como los hombres, sino hacer de los hombres y de las mujeres «personas completas». Según ella, «la igualdad real entre los sexos conduciría a transformaciones radicales en la estructura social de las naciones industrializadas».

Ningún país, sea socialista o capitalista, ha previsto todavía de manera rigurosa los cambios necesarios e inevitables que la macroestructura debería sufrir si una igualdad real tuviera lugar. Es sin duda una de las cuestiones más apasionantes que tienen que afrontar todos aquellos que crean que la sociedad se enriquecerá el día en que utilizará el conjunto de las capacidades de los dos sexos. 